\title{
Measuring intraepithelial lymphocytes, surface area, and volume of lamina propria in the jejunal mucosa of coeliac patients
}

\author{
M. GUIX, J. M. SKINNER, AND R. WHITEHEAD 1 \\ From the Flinders University of South Australia, South Australia
}

SUMMARY An accurate morphometric method is described for quantifying the intraepithelial lymphocytes (IEL), the area of the epithelium, and the volume of the lamina propria in jejunal mucosa of coeliac patients. All measurements are related to a unit-length of muscularis mucosa which is unaltered by the disease process. The results show a significant decrease in the epithelial surface area and an increase in the volume of the lamina propria in coeliac jejunal mucosa compared with normal levels, even after treatment. The number of IEL is the same as normal before or after treatment. Other workers have shown an apparent increase in IEL in untreated disease which returns to normal levels after therapy. This discordance is explained and the importance of accurate quantitative methodology is stressed.

The number of intraepithelial lymphocytes (IEL) in the jejunal mucosa of coeliac patients has been measured by several authors who have claimed that they are increased. This increase has been used both as a diagnostic indicator and to support certain immunological theories of origin of the mucosal lesion (Ferguson and Murray, 1971; Otto, 1973; Holmes et al., 1974; Lancaster-Smith et al., 1976). In all these measurements the number of IEL has been related to a number of epithelial cells or to a given length of the epithelial layer. The epithelial layer is, however, severely altered in coeliac disease and consequently is itself a variable and should not be used in this way as a unit of measurement of abnormality of other parameters.

\section{Methods}

\section{SUBJECTS}

Jejunal biopsies from five normal individuals, six untreated coeliac patients, and six treated patients who had been on gluten free diet for one year were examined. The diagnosis of coeliac disease was based on clinical and morphological grounds - that is, there was malabsorption, crypt hyperplasia and total villous atrophy of the jejunal mucosa when

'Address for correspondence: Department of Pathology, Flinders Medical Centre, Bedford Park, South Australia, 5042.

Received for publication 9 October 1978 patients were first seen, and both clinical and morphological improvement after a gluten free diet with the appearance of clinical symptoms and morphological abnormalities after further gluten challenge. Biopsies were taken with a Crosby capsule under radiological control from a point just distal to the ligament of Treitz, and all processed for histology, according to the same technique, so that any errors in cell counting introduced by variability of tissue shrinkage and section thickness were minimised. This included timed fixation in buffered formalin $(4 \%)$ followed by routine paraffin embedding and sectioning on the same microtome, at the same setting of $4 \mu$. Sections from all the cases were then stained together by haematoxylin and eosin.

All biopsies had to include the muscularis mucosa which was used as the unit against which all other measurements were made. A grid (Fig. 1) was placed in the eyepiece of the microscope and counts of different fields were made in each case. According to the 'quotient of accumulative addition of values' (Dunnill 1968), it was demonstrated that seven different fields needed to be counted in each case. Figure 2 shows a typical graph when epithelium and lamina propria are being assessed. It can be seen that after 154 intercepts in the epithelial layer and 94 points on the lamina propria the quotient remains stable and this determines the minimum number of fields which have to be evaluated. The unit-length of muscularis mucosa in each field was 


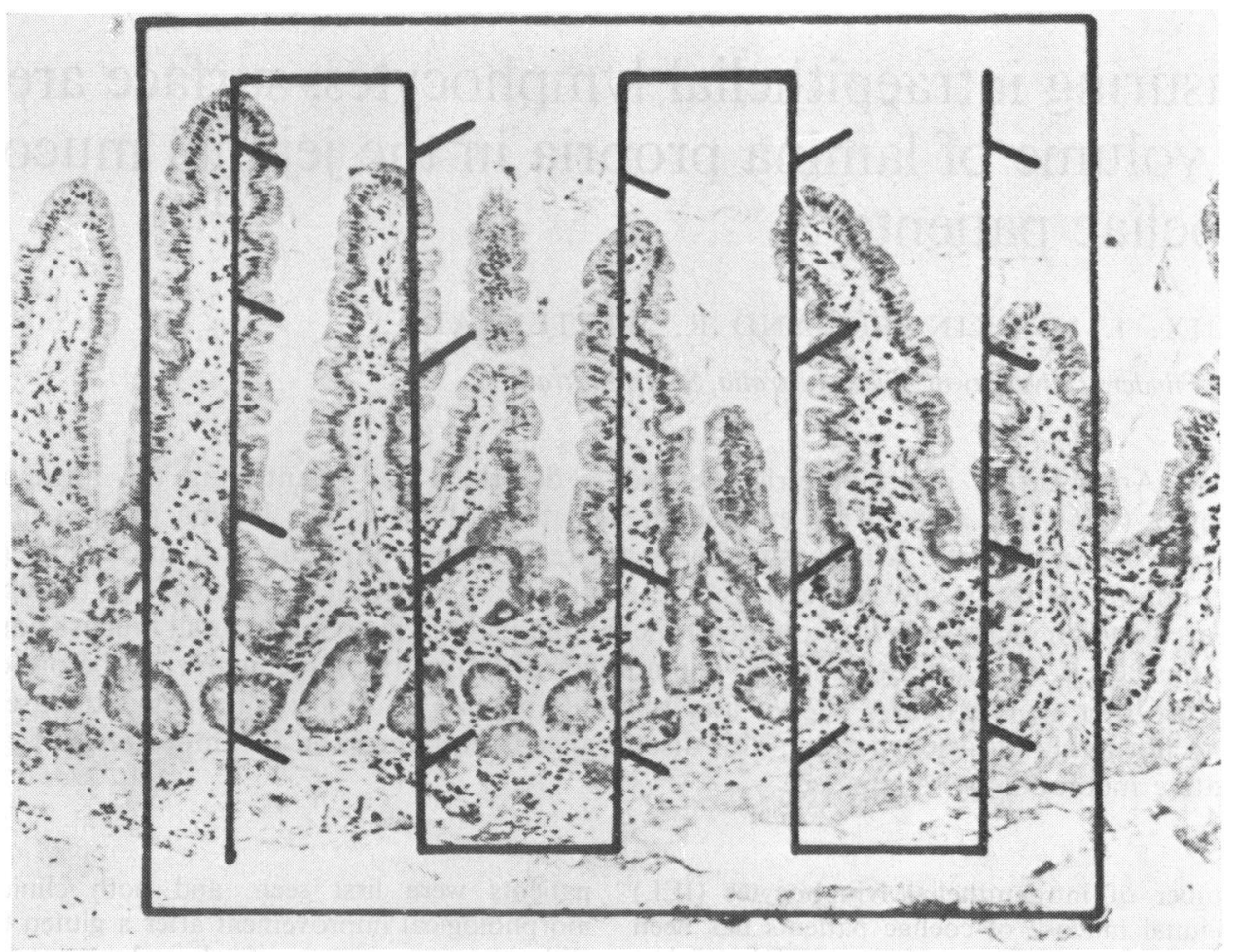

Fig. 1 Unit-length of muscularis mucosa is given by the five intercepts of the grid's line ( $\times 10$ original magnification).

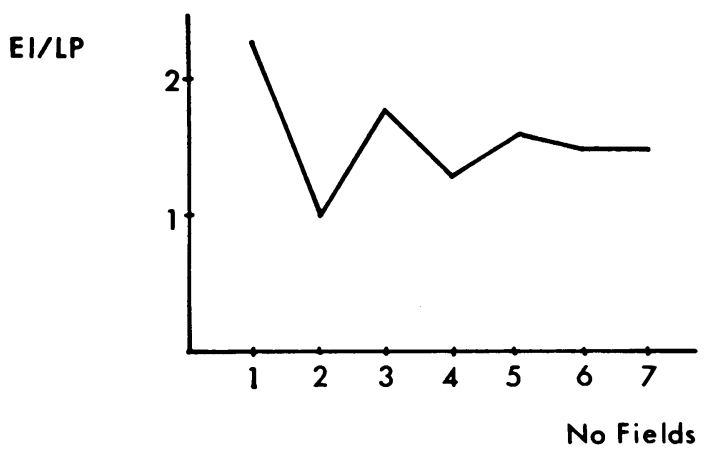

Fig. 2 Graph of the quotient of accumulative addition of values between the number of epithelial intercepts and the number of points in the lamina propria $(E I / L P)$.

The quotient remains stable after seven fields examined.

that which was intercepted five times by the grid's line. Intraepithelial lymphocytes were counted in the epithelium (including crypts) which was related to the unit-length of the muscularis mucosa. With the same technique the surface area of the epithelium was estimated. It was derived from the number of intercepts made by the grid's line on the basement membrane of the epithelium. As it is not possible, particularly in abnormal biopsies, to ascertain with any accuracy where the surface epithelium begins and the crypt epithelium ends measurement of these as separate entities was not attempted. An estimate of the volume of the lamina propria was given by the number of points-that is, the end points of the short lines-which fell onto the lamina propria.

Student's $t$ test was used for statistical analysis using the programmes in Statistical Package for Social Sciences (Nie et al., 1975) and a DEC 10 computer (Digital Equipment Corporation). The differences were significant when $P<0.05$.

\section{Results}

The results of the examination are seen in Table 1. The mean values and standard deviations of the IEL, the surface area of the epithelium, and the volume of the lamina propria are given in Table 2. The statistical analysis comparing normal subjects with untreated and treated coeliacs showed no significant difference in IEL while, in relation to 
Table 1 Results of different measurements in each case

\begin{tabular}{lll}
\hline Epithelial intercepts & Lamina propria points & $\begin{array}{l}\text { Intraepithelial } \\
\text { lymphocytes }\end{array}$ \\
\hline Normal subjects & & \\
169 & 82 & 604 \\
133 & 87 & 420 \\
187 & 79 & 427 \\
154 & 95 & 463 \\
127 & 107 & 333 \\
Untreated patients & & \\
61 & 186 & 572 \\
93 & 179 & 441 \\
94 & 112 & 357 \\
102 & 187 & 385 \\
118 & 169 & 454 \\
153 & 164 & 694 \\
Treated patients & & \\
97 & 140 & 366 \\
182 & 108 & 404 \\
112 & 124 & 420 \\
150 & 148 & 450 \\
110 & 160 & 364 \\
101 & 165 & 512 \\
\hline
\end{tabular}

surface area of epithelial layer and volume of lamina propria, significant differences were found. The $P$ values are given in Table 3.

\section{Discussion}

Usually IEL have been counted in relation to a fixed number of epithelial cells (Ferguson and Murray, 1971; Otto, 1973; Lancaster-Smith et al., 1976) or to a fixed length of epithelial layer (Holmes et al., 1974). Accordingly, Ferguson (1977) has proposed that the normal range is between six and 40 IEL per 100 epithelial cells. This is clearly a wide range; nevertheless, these authors have shown that the ratio of IEL to epithelial cells is significantly increased in both untreated and treated coeliac patients when compared with normal subjects. This they interpreted as being due to an actual increase in the number of IEL. The same result would be obtained, however, if the number of lymphocytes for a given length of mucosa stayed the same, but the epithelial cells decreased in number.

Our results do, in fact, show a significant overall decrease in the epithelial area of jejunal mucosa
Table 3 Statistical analysis ( $t$ test) between normal vs. untreated and treated coeliacs for IEL, A. Epith, andVLP

\begin{tabular}{llll}
\hline & IEL & A. Epith. & VLP \\
\hline Normal vs. untreated & NS & 0.016 & 0.000 \\
Normal vs. treated & NS & 0.025 & 0.001 \\
\hline
\end{tabular}

NS: not significant. Abbreviations as in Table 2.

and a parallel increase in the volume of the lamina propria in coeliac patients. The redistribution of epithelial cells in the evolution of the flat mucosa and associated crypt hyperplasia determines that IEL, being lumenopetal (Ferguson, 1974), will occur in greater numbers per unit of lumenal epithelium as opposed to total epithelium. However, because of its alteration, the epithelial layer in coeliac disease cannot be used as a unit of measurement for counting the total number of IEL. The ratio of IEL to lumenal epithelial cells nevertheless serves as a useful indicator of overall epithelial cell reduction in coeliac disease. It is important, however, that the correct interpretation of this ratio be made. By relating measurement to the muscularis mucosa, which is unaltered in coeliac disease, we have shown that IEL are, in fact, not increased in the mucosa as a whole. This has intrinsic factual importance, particularly with respect to consideration of both the function of IEL and the pathogenetic mechanisms involved in coeliac disease. For example, lack of evidence for an increase in IEL in coeliac disease detracts from the argument that they are important in the mechanism of epithelial cell damage.

It is necessary also to emphasise the differences in the surface epithelial area and volume of lamina propria between normal subjects and treated coeliacs. Even when gluten is absent from the diet in coeliac disease the mucosa is still demonstrably normal. This parallels the finding (Guix et al., 1978) that there is, in these circumstances, evidence of an on-going humoral immune reaction, possibly in relation to lumenal antigens other than gluten.

This study was supported in part by a grant from Fundación Juan March (Spain), and the Flinders Medical Centre (South Australia).

Table 2 Means $(\bar{X})$ and standard deviations $(s)$ of the three parameters measured in this study

\begin{tabular}{|c|c|c|c|c|c|c|}
\hline & \multicolumn{2}{|l|}{$I E L$} & \multicolumn{2}{|c|}{ A. Epith. } & \multicolumn{2}{|l|}{$V L P$} \\
\hline & $\bar{X}$ & $s$ & $\bar{X}$ & $s$ & $\vec{X}$ & $s$ \\
\hline $\begin{array}{l}\text { Normal subjects } \\
\text { Untreated patients } \\
\text { Treated patients }\end{array}$ & $\begin{array}{l}449 \\
494 \\
419\end{array}$ & $\begin{array}{c}98 \cdot 74 \\
125 \cdot 2 \\
55 \cdot 98\end{array}$ & $\begin{array}{l}154 \\
103 \\
125\end{array}$ & $\begin{array}{l}24 \cdot 92 \\
30 \cdot 56 \\
33 \cdot 69\end{array}$ & $\begin{array}{r}90 \\
166 \\
140\end{array}$ & $\begin{array}{l}11 \cdot 27 \\
28 \cdot 07 \\
21 \cdot 74\end{array}$ \\
\hline
\end{tabular}

IEL: intraepithelial lymphocytes. A. Epith.: area of epithelial surface. VLP: volume of lamina propria, each expressed as a ratio to a fixed unit of muscularis mucosa. 


\section{References}

Dunnill, M. S. (1968). Quantitative methods in histology. In Recent Advances in Clinical Pathology, pp. 401-416. Series 5. Edited by S. C. Dyke, Churchill: London.

Ferguson, A. (1974). Lymphocytes in Coeliac disease. In Coeliac Disease, pp. 265-276. Edited by W. I. J. M. Hekkens and A. S. Pena. Sternfert-Kroese: Leyden.

Ferguson, A. (1977). Intraepithelial lymphocytes of the small intestine. Gut, 18, 921-937.

Ferguson, A., and Murray, D. (1971). Quantitation of intraepithelial lymphocytes in human jejunum. Gut, 12, 988-994.

Guix, M., Skinner, J. M., and Whitehead, R. (1978). Ultrastructural analysis of plasma cells in coeliac patients. (Submitted to Gut.)
Holmes, G. K. T., Asquith, P., Stokes, P. L., and Cooke W. T. (1974). Cellular infiltrate of jejunal biopsies in adult coeliac disease in relation to gluten withdrawal. Gut, 15, 278-283.

Lancaster-Smith, M., Packer, S., Kumar, P. J., and Harries, J. T. (1976). Cellular infiltrate of the jejumun after reintroduction of dietary gluten in children with treated coeliac disease. Journal of Clinical Pathology, 29, 587-591.

Nie, N. H., Hadlei Hull, C., Jenkins, J. G., Steinbrenner, K., and Bent, D. H. (1975). Statistical Package for Social Sciences. 2nd Edition. McGraw-Hill: London.

Otto, H. F. (1973). The intraepithelial lymphocytes of the intestinum. Morphological observations and immunologic aspects of intestinal enteropathy. Current Topics in Pathology, 57, 81-121. 